\title{
DÜBLIN
}

Technological University Dublin

ARROW@TU Dublin

\section{Simulation-based Optimisation Model for the Lean Assessment in SME: A Case Study}

\author{
Amr Arisha \\ Technological University Dublin, amr.arisha@tudublin.ie \\ Amr Mahfouz \\ Technological University Dublin, amr.mahfouz@tudublin.ie \\ John Shea \\ Technological University Dublin, jossnjuice@gmail.com
}

Follow this and additional works at: https://arrow.tudublin.ie/buschmarcon

Part of the Business Administration, Management, and Operations Commons, Industrial Engineering Commons, Operational Research Commons, Other Business Commons, and the Systems Engineering Commons

\section{Recommended Citation}

Arisha, A., Mahfouz, A., Shea, J.: Simulation-based Optimisation Model for the Lean Assessment in SME: A Case Study. Winter Simulation Conference, 2011.

This Conference Paper is brought to you for free and open access by the School of Marketing at ARROW@TU Dublin. It has been accepted for inclusion in Conference papers by an authorized administrator of ARROW@TU Dublin. For more information, please contact arrow.admin@tudublin.ie, aisling.coyne@tudublin.ie, gerard.connolly@tudublin.ie. Funder: College of Business 


\title{
SIMULATION BASED OPTIMISATION MODEL FOR THE LEAN ASSESSMENT IN SME: A CASE STUDY
}

\author{
Amr Mahfouz \\ John Shea \\ Amr Arisha \\ 3S Group, College of Business \\ Dublin Institute of Technology (DIT) \\ Aungier Street, Dublin 2, IRELAND
}

\begin{abstract}
Due to their space limitation and small production scale, small and medium enterprises (SME) are vulnerable to rapid changes. Lean principles are considered as effective improvement approach to eliminate system's waste and inefficiencies. Although much of the academic materials have addressed the lean practices into large, global companies, they can still be adjusted to SMEs. Risks are usually associated with lean implementation process due to the drastic required changes in business policies and operations. Simulation can be successfully used to predict the impact of the proposed changes ahead of the implementation which helps to mitigate risks. Integrating simulation with optimization techniques provides optimum settings of the lean factors prior to the go live stage. In this study, simulation based optimization model was developed to optimize a set of parameters of lean SME against three performance measures - cycle time, WIP (work in process) and workforce utilization. Results showed constructive insights.
\end{abstract}

\section{INTRODUCTION}

Lean manufacturing practices aim to reduce all forms of waste and inefficiency from production flow towards achieving efficient and flexible systems (e.g. excess inventory, unnecessary processing steps, underutilization of people and others) (Womack and Jones 1996). Various lean applications have been represented and adopted around SMEs; Kanban, pull systems, cell layout, total productive maintenance and others (Hicks 2007). A recent study illustrates the possible increasing in utilization within a pine making factory through organizing the workplace using 5S principle (Mo 2009). The author shows that a $30 \%$ increase of system efficiency can be achieved by organizing the production plant. In another application in a pumps and valves manufacturing company, reduction of inventory by $15 \%$ and increasing in productivity by $10 \%$ have been achieved by applying various lean practices such as Kanban, pull system and cell layout (Kumar et al. 2007).

Recent research emphasized on the need of simulation modeling in the appraisal process of lean implementation due to many reasons including (Diamond et al. 2002; Adams et al. 1999):

1. Identifying the involved factors and parameters in the manufacturing process.

2. Exploring the various opportunities of process improvement.

3. Predicting the impacts of the proposed changes before implementation.

4. Reducing the risks of the implementation process.

5. Mapping the future state of organizations' - value stream mapping.

6. Assessing the interaction influence between system's components and parameters. 
The benefits of using simulation technique as part of lean and six sigma projects was emphasized by Ferrin, Miller and Muthler (2005). Simulation offers a more thorough analysis of the system's data including the examination of parameters' variability, uncertainty in operations, and the estimation of a proper probability distribution that statistically fits the data set (Arisha and Young 2004; Mahfouz, Hassan and Arisha 2010). This kind of in-depth data analysis enables simulation to model systems' future state map showing the ideal state that the system can pursue over time. The advantage of using a simulation approach in the lean context does not stop at the phase of developing a future state map, but also extended to selecting the best alternative to the current system status. Such selection is done by carefully designed simulation experiments integrated with optimization tools (i.e., Taguchi and response surface methods).

In this paper, an industry-based case is represented to show the importance of using simulation optimization in the lean evaluation process. Three lean practices related to demand management, preventive maintenance, labors capacity and product flow are highlighted and evaluated using cycle time, WIP (work in process) and labors utilization as performance measures. Integrated definition model (IDEF0) in conjunction with simulation and response surface method have been developed to characterize the factory under study - a packaging manufacturing system. Four process parameters representing the lean practices will be analyzed and optimized using the selected performance indicators.

\section{FACTORS INFLUENCING LEAN IN THE PACAGING MANUFACTURING COMPANY}

\subsection{Company Overview}

BPP is a company specialized in food and pharmaceutical packaging. It produces printed plastic bags and films for a wide spectrum of customers (e.g. supermarket chains, wholesaler food suppliers, pharmaceutical companies, export business and others). The company has two independent production facilities located in two different places. The process starts with yielding polyethylene films in roll form, followed by the printing process based on customers' specifications and finally packing and distributing products to end customers. Recently, the company developed new processes such as lamination and multilayer extrusion in order to compete with the cutting edge packaging technology, Figure 1. Each product has different production routes based on its specifications and characteristics such as height, thickness, quantity needed and extrusion weight.

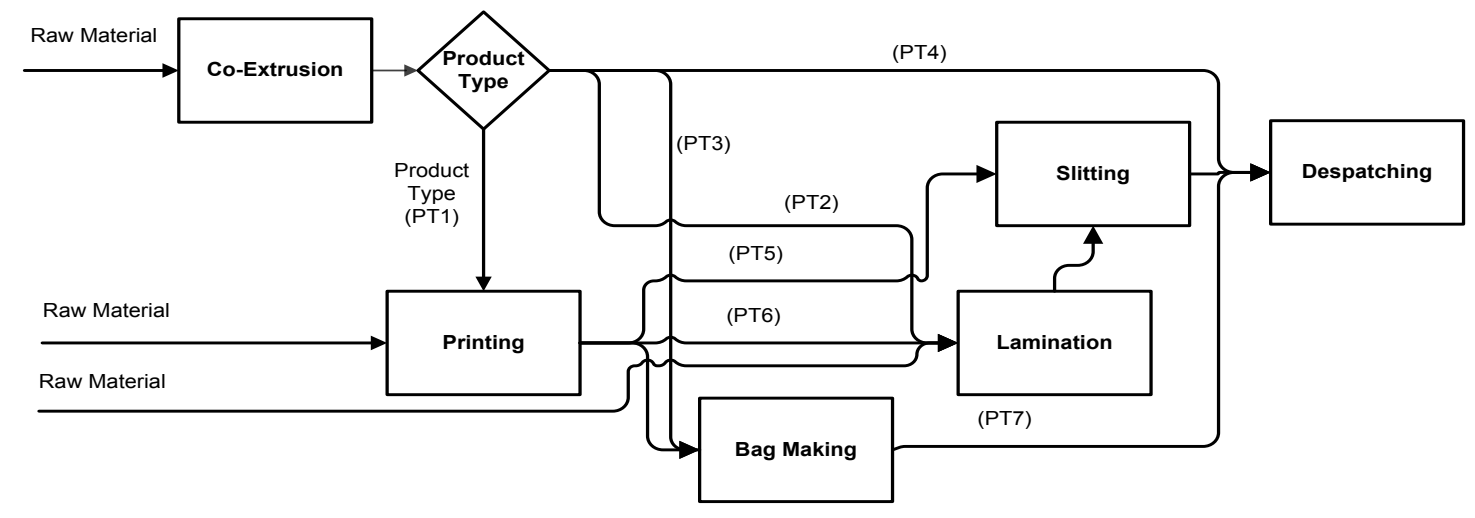

Figure 1: BPP main manufacturing activities

Meeting orders' due-date represents the first priority for BPP to keep its competitive advantages and retain its customers' loyalty. Providing more reliable and waste free leaner manufacturing processes with shorter cycle times is the main objective that BPP pursues. As a result, it became crucial to deal with a re- 
duction in cycle time and WIP (main source of waste) as well as facilitate the product flow through the production process. The split location of the company's production facilities, fluctuation of customer demands, the high frequency of machines breakdown and labors underutilization make the whole process unreliable and inefficient.

\subsection{Facility Layout}

The company has two separate production facilities that have different machines and storage locations as indicated in Figure 2. The production processes are distributed around the two facilities which results in a more complicated products flow and long cycle time, even with the products that have very simple production routes. For instance, the routing could be Extrusion, Printing, Slitting, Lamination and finally Bag-making. This may seem a simple route, but the issue was that Extrusion was in Plant 1, Printing, Slitting and Lamination were located in Plant 2, and the final bag-making station was located back in Plant 1. In effect, the movements between the two plants elongates the cycle time by 48 hours more than necessary. Moreover, the unorganized transportation schedule between the two plants causes inventory excess in the dispatching area and negatively influences the company's delivery performance. Since transportation is addressed as one of the seven wastes that lean targets in the production systems, various lean practices (e.g. Kanban, pull strategy, synchronization and others) have focused on effective management strategies for the transportation issue (Wilson 2010). Most of these practices attempt to identify the most convenient transportation capacity and frequency that lead to balance the trade-off between transportation cost and time. Three transportation strategies are proposed by the studied company to mitigate the negative impact of the adopted transportation strategy. Various frequency rates are suggested to the three proposed strategies ( 2 trips a day, one trip a day or one trip every two days), depicted in Table 1. Using the proposed simulation-optimization model, the three transportation frequencies are investigated against the studied performance indicators.

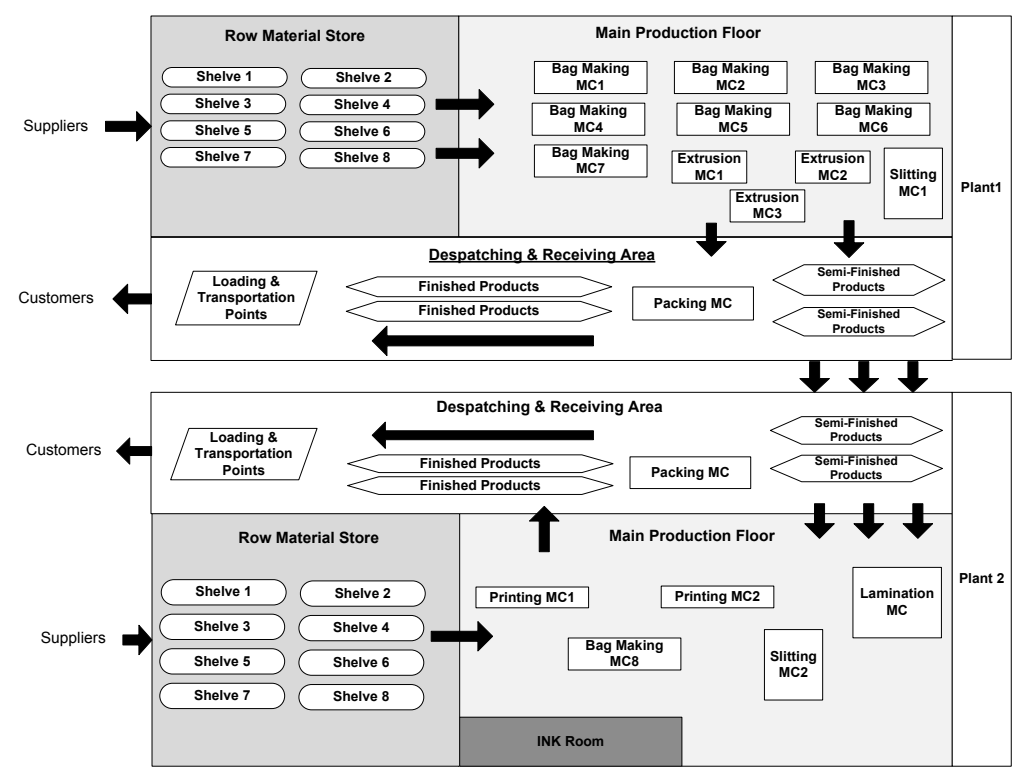

Figure 2: BPP planets layout

\subsection{Preventative Maintenance (PM)}

Frequent machine breakdowns contributes negatively to product quality. That in return encounters extra cost and time to the operations due to the re-work expenses. The adoption of PM plans leads to a speeding up of a product's lead times and increases their quality level. In a lean context, preventive maintenance is a pivotal element for several lean practices such as OEE (overall equipment effectiveness), TPM 


\section{Mahfouz, Shea and Arisha}

(total productive maintenance) and visual management (Wilson 2010). From company's maintenance records, it was found that no plan for preventive maintenance is applied and instead instant repairs for machine breakdowns are done. Given the increasing figures of company's sales and the constantly growing amount of orders, the company recognized that it cannot afford the production disturbances due to the frequent machines breakdown. Hence, two PM plans are suggested and evaluated against the current system state (no adopted PM plan). According to the first PM plan, every machine is maintained for one week every three months, while in the second plan the maintenance is repeated every six months. Although the company's maintenance manager has estimated that the main time between failures (MTBF) will be increased by $70 \%$ and $30 \%$ in applying the first and second plans respectively, the decision of which plan is better should be taken cautiously. The short frequent PM may harm the company's performance due to the repeated machines' interruptions. Simulation-optimization will be employed to examine which plan is optimal, based on the studied system's performance.

\subsection{Demand Management}

The high variability of demand-forecasting due to markets' dynamic behavior often creates numerous ripple effects on manufacturing performance. Lean successfully moves operations away from depending on forecasts to rely on other strategies such as the pull system, demand leveling and Kanban. BPP's sales team receives customer orders with several products' kinds, specifications and quantities in unorganized and random patterns. Currently, customer orders are forwarded directly to the production planning team, who trie to chase the demand fluctuation by continuous changes in their resources and material capacities. Despite this, high customer satisfaction can be achieved by applying the chasing strategy, inconsistent production and capacity plans result in high production costs and sometimes underutilization of the materials and resources. Demand leveling strategy is proposed in BPP as an effective lean practice that identifies a constant demand rate to be produced in a specific time. It results in a stable resource capacity which leads to a proper labor utilization and cost minimization. Three different rates are investigated and illustrated in Table 1. In addition, three levels of staff capacity have also been examined as an important factor for the demand leveling strategy. The values of the factor's levels are identified based on various discussions with the company's operations manager.

Table1: BPP system factors and levels

\begin{tabular}{|c|c|c|c|c|}
\hline Factor & Unit & Level 1 & Level 2 & Level 3 \\
\hline Demand Rate (DR) & Products/Hour & 2 & 1 & 0.5 \\
\hline Preventive Maintenance (PM) & Months & 0 & 3 & 6 \\
\hline Production Staff Capacity (SC) & Number & 15 & 30 & 40 \\
\hline Transportation Frequency (TF) & Trips/Day & 2 & 1 & 0.5 \\
\hline
\end{tabular}

\section{BUSINESS PROCESS MODELLING}

Taking into account the complexity of BPP's manufacturing system and its multiple input, output, controls and mechanisms, IDEF0 emerges as a powerful tool for modeling such intricate systems. A hierarchical modeling approach using IDEF0 allows users (e.g. strategic managers, operational engineers and system analyzers) to comprehensively understand the sequence of system's functions. An activity block which is the main unit for IDEF0 describes the main function of the process. ICOMs (Input, Control, Output and Mechanism) are represented by horizontal and vertical arrows, as depicted in Figure 3. Process control (top arrow) can be company regulations, standards or legislation, whereas process mechanisms are usually the agents which facilitate the activity (e.g., People and automated tools). Further information about IDEF0 can be found in Christopher (1998). 


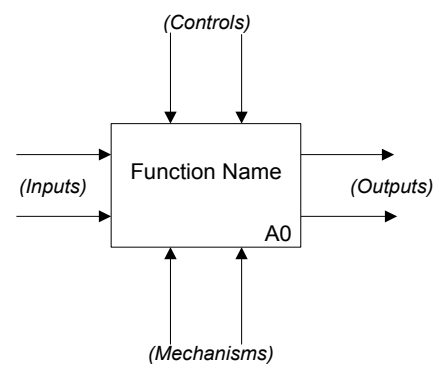

Figure 3: Basic IDEF0 constructs

IDEF0 is used as a modeling approach to conceptualize BPP's processes before developing the simulation model. Figure 4 shows the top level of the conceptual model (IDEF0) which indicates the sequence of activities, the inputs such as raw material, the mechanisms (operators and machines), the controls (products specs and quality standards) and the output (finished products). IDEF0 allows the user to comprehensively follow the undertaking production processes, in this case extrusion and printing, laminating, slitting, bag-making and finally dispatch. In addition, the routes of products through the production processes are clearly illustrated which make the simulation modeling process easier and effective.

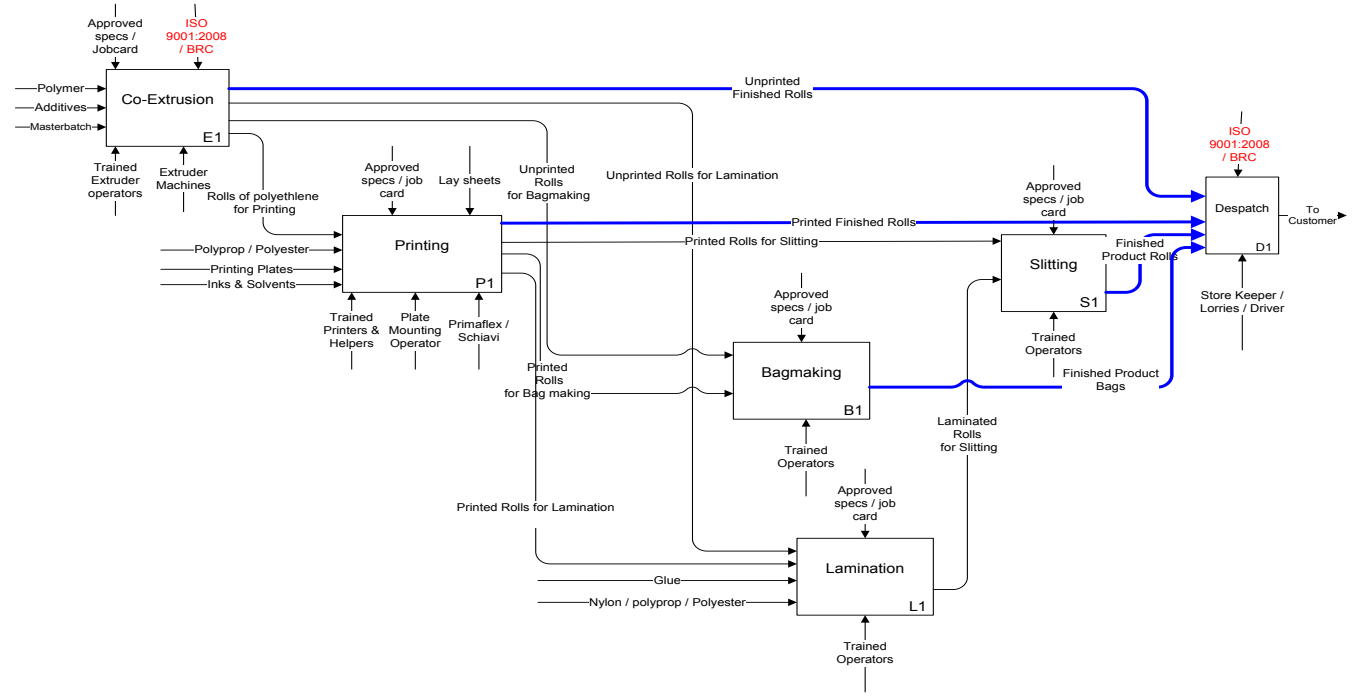

Figure 4: IDEF0 diagram illustrating the conceptual model of packaging plant

\section{MODELLING AND SIMULATION}

In this study a probabilistic model is required in order to account for uncertainty in customers demand, products specifications, products' operation time, and the unpredicted breakdowns of resources. The stochastic technique of discrete-event simulation is selected due to its capability of manipulating the variability and uncertainty of a system's parameters. Simulation model was developed based on BPP's conceptual model, Figure 4. The model has described the products movement through the production line and the resources (e.g. machines, workstations) used to produce them. Resources are characterized by their capacity, breakdown schedules, repair time and preventive maintenance scheme, whilst the attributes of the products are arrival time, processing time and product configurations. Logical entities have simulated the decisions for creating, joining, splitting, buffering and branching entities. Each product specification has its own statistical arrival distribution and routing, while product processing time is a function of product weight and length. Products routing is considered an important issue in this model as there is no fixed route for the products due to the wide variety of their specifications (500 different products type). There was a need for a database containing unique products information such as product code, routing and spe- 


\section{Mahfouz, Shea and Arisha}

cifications (i.e., weight and length). The studied lean practices are evaluated through the simulation model by changing various parameters (e.g. production level and staff capacity) or adding new resources and entities as in the preventive maintenance case.

In an effort to make the decisions taken based on the simulation models more accurate, efficient methods of verification and validation are conducted. For the verification process, in addition to the decomposition model (i.e. to verify every group of blocks), a simulation software built-in debugger is applied. A decomposition approach is effective in the detection of errors and insuring that every block functions as expected. The studied model has been validated using two techniques; 'Face Validation' that was performed by interviewing managers and manufacturing teams in order to validate simulation model results and 'Comparison Testing' which done by comparing the model output with the system output under identical input conditions $-15 \%$ average percentage of deviation.

\section{RESULT ANALYSIS}

Three goals are pursued in the analysis stage; (i) substantiate a valid relationship between the identified lean factors and their corresponding response variables (i.e. cycle time, WIP and labor utilization), (ii) identify the critical factors that have a significant influence on the response functions and finally (iii) optimize the settings of the critical parameters for each response function. For the model to reach its steady state, a warm-up period (100 hours) is applied. Since a large number of experiments are required to determine the optimum combinations of the studied parameters $\left(3^{4}=81\right)$, three levels orthogonal array was selected. The Taguchi method uses orthogonal array from the design of experiments theory to study a large number of variables with a small number of experiments (Phadke,1989). Hence, $\mathrm{L}_{27}\left(3^{13}\right)$ design for controllable factors was selected and analyzed to develop the experimental matrix in Table 2 (Sahoo, Tiwari and Keliham 2008). Each experiment result is an average of ten independent replications.

The main and interaction effects of the studied factors were analyzed using $95 \%$ confidence interval, Tables 3,4 and 5. The main effect analysis is conducted by changing one single factor at a time while all other parameters are fixed, whereas the interaction effect is based on changing two or more factors and examine their impacts on the response functions.

Identifying constant demand rate (i.e. factor A) has recorded significant impacts on the three studied metrics while the capacity of labors (factor $\mathrm{C}$ ) shows an effect on the labors utilization metric $(\mathrm{P}<0.005)$. On the other hand, the interaction between factors $\mathrm{A}$ and $\mathrm{C}$ has only shown influence on the cycle time metric. This impact can be explained as the increasing in demand rate rushes the production process with large number of customer orders, which overloads its machines and labors and sometimes causes bottlenecks and large buffers between workstations. Labor utilization is also influenced by changing labor capacity under these conditions. The sensitivity of the performance metrics to the changing in demand rates is also referred to the complexity of company's production process especially with the large number of products' specifications and their different routings across the production facilities.

Despite highlighting that preventive maintenance has a considerable influence on the machines' failure rates and their reliability, it does not show significant effect on any of the studied metrics. This can be described as each workstation contains 2 or more identical machines which reduce the impact of their breakdowns on products flow and cycle time. The rate of products' transportation between the two plants is an important parameter regarding the products flow and companies' flexibility, according to the company's operation manager. Its small $\mathrm{P}$ values in Tables 3 and 4 emphasizes this fact, however it cannot be considered a statistical significant parameter since its $\mathrm{P}$ value is still $>0.005$. After identifying the main and interaction effects of the studied lean factors, an optimization process for the factors' settings will be pursued using response surface methodology (RSM). RSM will be employed to establish a robust regression model and find optimal results for the studied factors. 
Mahfouz, Shea and Arisha

Table 2: Design matrix for factors combination under three responses functions

\begin{tabular}{|c|c|c|c|c|c|c|c|}
\hline \multirow{2}{*}{ Experiments } & \multirow{2}{*}{ DR } & \multirow{2}{*}{ PM } & \multirow{2}{*}{$\mathrm{SC}$} & \multirow{2}{*}{$\mathrm{TF}$} & \multicolumn{3}{|c|}{ Responses Functions } \\
\hline & & & & & Cycle time & WIP & Staff utilization \\
\hline 1 & 1 & 2 & 1 & 1 & 92.215 & 29.275 & 0.981 \\
\hline 2 & 1 & 1 & 2 & 2 & 42.380 & 21.870 & 0.7 \\
\hline 3 & 1 & 1 & 3 & 3 & 41.957 & 23.884 & 0.550 \\
\hline 4 & 1 & 1 & 1 & 2 & 40.640 & 21.670 & 0.720 \\
\hline 5 & 1 & 2 & 2 & 3 & 44.237 & 24.034 & 0.665 \\
\hline 6 & 1 & 2 & 3 & 1 & 42.211 & 25.827 & 0.538 \\
\hline 7 & 1 & 2 & 1 & 3 & 88.792 & 27.546 & 0.988 \\
\hline 8 & 1 & 3 & 2 & 1 & 74.692 & 26.297 & 0.961 \\
\hline 9 & 1 & 3 & 3 & 2 & 38.895 & 21.646 & 0.730 \\
\hline 10 & 1 & 3 & 1 & 2 & 41.184 & 22.947 & 0.693 \\
\hline 11 & 2 & 1 & 2 & 3 & 42 & 11.230 & 0.600 \\
\hline 12 & 2 & 1 & 3 & 1 & 29.300 & 7.770 & 0.440 \\
\hline 13 & 2 & 1 & 1 & 2 & 55.600 & 12 & 0.930 \\
\hline 14 & 2 & 2 & 2 & 3 & 21.530 & 5.455 & 0.470 \\
\hline 15 & 2 & 2 & 3 & 1 & 24.024 & 7.416 & 0.381 \\
\hline 16 & 2 & 2 & 1 & 3 & 27.141 & 6.065 & 0.860 \\
\hline 17 & 2 & 3 & 2 & 1 & 45.801 & 8.825 & 0.959 \\
\hline 18 & 2 & 3 & 3 & 2 & 23.408 & 6.740 & 0.495 \\
\hline 19 & 2 & 3 & 1 & 1 & 39.568 & 7.796 & 0.934 \\
\hline 20 & 3 & 1 & 2 & 2 & 14.904 & 3.193 & 0.371 \\
\hline 21 & 3 & 1 & 3 & 3 & 15.332 & 2.935 & 0.264 \\
\hline 22 & 3 & 1 & 1 & 3 & 16.096 & 2.939 & 0.740 \\
\hline 23 & 3 & 2 & 2 & 1 & 11.115 & 2.854 & 0.317 \\
\hline 24 & 3 & 2 & 3 & 2 & 13.209 & 3.084 & 0.326 \\
\hline 25 & 3 & 2 & 1 & 1 & 12.092 & 2.778 & 0.615 \\
\hline 26 & 3 & 3 & 2 & 2 & 11.495 & 2.585 & 0.330 \\
\hline 27 & 3 & 3 & 3 & 3 & 13.390 & 2.688 & 0.252 \\
\hline
\end{tabular}

Table 3: Main and Interaction effect of lean factors against the cycle time

\begin{tabular}{|c|c|c|c|c|c|}
\hline Source & Sum of Squares & $d f$ & Mean Square & F Value & P-value \\
\hline A-DR & 7425.64 & 1 & 7425.64 & 34.62 & 0.0001 \\
\hline B-PM & 25.29 & 1 & 25.29 & 0.12 & 0.7372 \\
\hline C-SC & 600.68 & 1 & 600.68 & 2.80 & 0.1201 \\
\hline D-TF & 1272.16 & 1 & 1272.16 & 21.27 & 0.0297 \\
\hline $\mathrm{AB}$ & 124.38 & 1 & 124.38 & 0.58 & 0.4611 \\
\hline $\mathrm{AC}$ & 2740.38 & 1 & 2740.38 & 27.66 & 0.0001 \\
\hline $\mathrm{AD}$ & 46.81 & 1 & 46.81 & 0.22 & 0.6487 \\
\hline $\mathrm{BC}$ & 255.66 & 1 & 255.66 & 1.19 & 0.2967 \\
\hline $\mathrm{BD}$ & 88.80 & 1 & 88.80 & 0.41 & 0.5320 \\
\hline $\mathrm{CD}$ & 95.53 & 1 & 95.53 & 0.45 & 0.5171 \\
\hline
\end{tabular}

Table 4: Main and Interaction effect of lean factors against WIP Level

\begin{tabular}{|c|c|c|c|c|c|}
\hline Source & Sum of Squares & $d f$ & Mean Square & F Value & P-value \\
\hline A-DR & 1824.48 & 1 & 1824.48 & 336.01 & 0.0001 \\
\hline B-PM & 4.05 & 1 & 4.05 & 0.75 & 0.4047 \\
\hline $\mathrm{C}-\mathrm{SC}$ & 2.71 & 1 & 2.71 & 0.50 & 0.4936 \\
\hline D-TF & 11.51 & 1 & 11.51 & 2.08 & 0.0752 \\
\hline $\mathrm{AB}$ & 2.26 & 1 & 2.26 & 0.42 & 0.5307 \\
\hline $\mathrm{AC}$ & 5.37 & 1 & 5.37 & 0.99 & 0.3396 \\
\hline $\mathrm{AD}$ & 2.91 & 1 & 2.91 & 0.54 & 0.4781 \\
\hline $\mathrm{BC}$ & 2.61 & 1 & 2.61 & 0.48 & 0.5012 \\
\hline $\mathrm{BD}$ & 0.82 & 1 & 0.82 & 0.15 & 0.7046 \\
\hline $\mathrm{CD}$ & 1.70 & 1 & 1.70 & 0.31 & 0.5856 \\
\hline
\end{tabular}




\section{Mahfouz, Shea and Arisha}

Table 5: Main and Interaction effect of lean factors against Utilization

\begin{tabular}{|c|c|c|c|c|c|}
\hline Source & Sum of Squares & Df & Mean Square & F Value & P-value \\
\hline A-DR & 0.35 & 1 & 0.35 & 22.61 & 0.0005 \\
\hline B-PM & 0.021 & 1 & 0.021 & 1.34 & 0.2697 \\
\hline C-SC & 0.40 & 1 & 0.40 & 25.46 & 0.0003 \\
\hline D-TF & 0.011 & 1 & 0.011 & 0.73 & 0.4108 \\
\hline $\mathrm{AB}$ & $9.737 \mathrm{E}^{-003}$ & 1 & $9.737 \mathrm{E}^{-003}$ & 0.63 & 0.4441 \\
\hline $\mathrm{AC}$ & $2.288 \mathrm{E}^{-003}$ & 1 & $2.288 \mathrm{E}^{-003}$ & 0.15 & 0.7079 \\
\hline $\mathrm{AD}$ & $3.488 \mathrm{E}^{-003}$ & 1 & $3.488 \mathrm{E}^{-003}$ & $2.244 \mathrm{E}^{-003}$ & 0.9630 \\
\hline $\mathrm{BC}$ & 0.036 & 1 & 0.036 & 2.32 & 0.1538 \\
\hline $\mathrm{BD}$ & 0.046 & 1 & 0.046 & 2.94 & 0.1119 \\
\hline $\mathrm{CD}$ & $3.630 \mathrm{E}^{-003}$ & 1 & $3.630 \mathrm{E}^{-003}$ & 0.023 & 0.8811 \\
\hline
\end{tabular}

\subsection{Response Surface Methodology}

RSM is a sequential procedure that allows fitting a series of regression models into the response function (Shang and Tadikamalla 2004). The technique seeks to estimate a functional relationship between one or more responses and a number of independent variables in order to explore the optimum operation conditions for the system (Sahoo, Tiwari and Mileham 2008). Using the values of the three response functions, Table 2, it was found that quadratic models fit the three functions, Equations 1,2 and 3.

Cycle Time $=-6.875+81.918 A-9.623 B+1.322 C-44.299 D+1.660 A B-0.939 A C+4.115 A D+0.158 B C+1.910 B D$

$-0.352 C D-14.741 A^{2}+0.067 B^{2}-0.012 C^{2}+19.454 D^{2}$

$W I P=1.108+5.671 A-0.954 B+0.137 C-5.214 D+0.224 A B-0.079 A C+1.026 A D+0.015 B C+1.183 B D-0.047 C D$ $+3.716 A^{2}-0.030 B^{2}-1.142 E^{-003} C^{2}+2.235 D^{2}$

Utilization $=0.9331+0.761 A-0.133 B-0.026 C-0.327 D-0.014 A B+1.632 E^{-003} A C-3.552 E^{-003} A D+1.876 E^{-004} B C+$ $0.043 B D-6.873 E^{-003} C D-0.256 A^{2}+4.063 E^{-003} B^{2}+1.12 E^{-004} C^{2}+0.102 D^{2}$

It is obvious that decreasing the demand rate and increasing the frequency of a product's transportation contribute significantly in decreasing the products' cycle time and WIP. On the other hand, increasing the demand rate and product transportation intervals with small resources capacity can increase the labors utilization.

In order to determine the optimal values of the response functions, the counters mesh was developed in Figures 5 (a), (b) and (c), showing the mesh surface for the regression coefficients of the three responses functions. The mesh surface is developed based on the results of the ANOVA model. The surfaces of Cycle Time and Utilization metrics are developed based on factors A and C (the most significant factors for the two metrics) while Factor D and A are selected for the WIP surface being the factors with lowest $\mathrm{P}$ values (more significant). The three mesh surfaces represented optimal settings of lean factors for each response function, shown in Table 6.

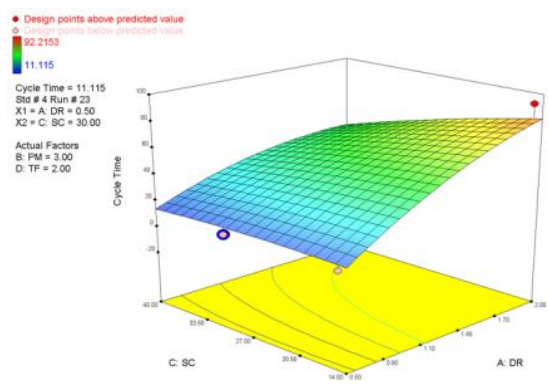

Figure 5 (a): 3D representation for cycle time

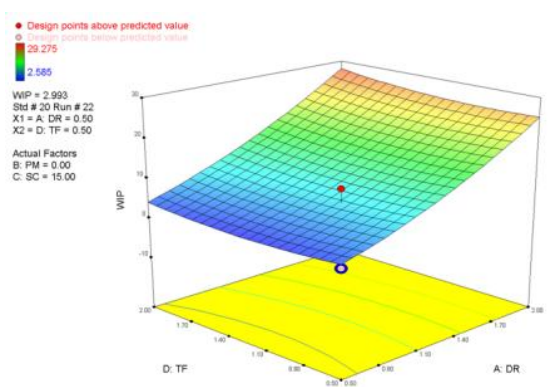

Figure 5 (b): 3D representation for WIP level 


\section{Mahfouz, Shea and Arisha}

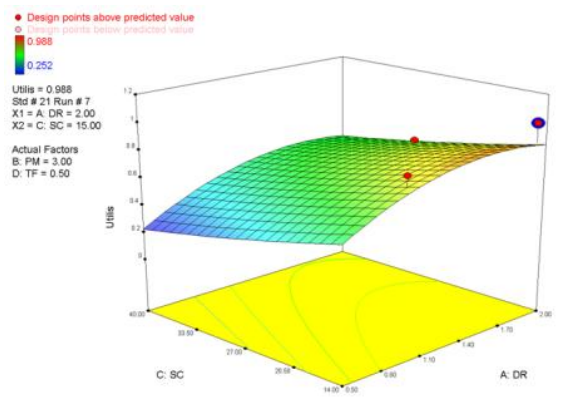

Figure 5 (c): 3D representation for Utilization

Table 6: Optimal values for response functions

\begin{tabular}{cccccc}
\hline Response Function & DR & PM & SC & TF & Function Value \\
\hline Cycle Time & 0.5 & 3 & 30 & 2.00 & 11.15 \\
WIP Level & 0.5 & 0 & 15 & 0.5 & 3 \\
Utilization & 2 & 3 & 15 & 0.5 & 0.98 \\
\hline
\end{tabular}

The optimal values of cycle time (11.15 days) and average WIP levels ( 3 products) are achieved by implementing the same production rate $(0.5$ product/hour $)$ with different settings for the other parameters. Increasing production rate to 2 products per hour and reducing the products transportation frequency to one trip every half an hour dramatically increased the staff utilization to reach $98 \%$, but at the same time it has increased the average cycle time to record 88.79 days and the WIP level to 27.56 products.

The results of the optimization phase have emphasized the aforementioned analysis for factors' main and interaction effects and the regression models in Equations (1, 2 and 3). The significance of the production rate, staff capacity and products' transportation frequency have been depicted regardless of the applied preventive maintenance plan. Despite that PM parameter has changed in the WIP metric $\left(2^{\text {nd }}\right.$ row), it does not contribute much in the WIP result which recorded slight increasing with other PM plans.

In the lean context, since the first priority is given to reduce the cycle time and WIP level, which are important elements that contribute to customer satisfaction and waste elimination respectively, the company was recommended to decrease its demand rate and its products' transportation frequency. These two actions contribute to decreasing the production bottlenecks and reducing the products' transportation time. Resources underutilization and the slow production process are the main drawbacks of these strategies. If the first company's priority is maximizing labor utilization, then increasing the demand rate in parallel with reducing labors capacity are the optimal settings. However, these decisions need to be taken cautiously as they negatively impact on products cycle time and WIP, which in turn decrease customer satisfaction and increase waste in the system.

Further research efforts are required to develop decision making models that can optimize the contradicted response functions simultaneously. Multi criteria decision making approaches are powerful techniques that can do the job at providing the best factor settings that can optimize various response functions at the same time.

\section{CONCLUSION}

In this study, simulation based optimization model have been developed to evaluate the lean implementation in packaging manufacturer. Four lean factors have been defined and examined against three response functions, cycle time, WIP and staff utilization representing the leanness performance in this case. The system was comprehensively modeled using IDEF0 modeling language then a discrete event simulation was developed to analyze the selected factors. Finally a response surface method has been used to optimize the response functions. The model has contributed significantly to develop a better understanding of 


\section{Mahfouz, Shea and Arisha}

the system dynamics (i.e. impact on overall performance) through the factor analysis phase. The demand rate appeared to have a contradicting impact on the three performance measures. A minimum cycle time and WIP level can be achieved when applying low demand rate. Products' transportation frequency and labors capacity have featured positively on the three performance metrics, while preventive maintenance factor shows less impact on performance.

\section{ACKNOWLEDGMENTS}

We would like to express our gratitude to the factory staff, in particular Mr. Imran Chishty for his support in phase of collecting data and also his valuable contribution in the conceptual modeling phase and system analysis.

\section{REFERNCES}

Adams, M., P. Componation, H. Czarnecki, and B. J. Schroer. 1999. "Simulation as a tool for continuous process improvement." In Proceedings of the 1999 Winter Simulation Conference, edited by P. A. Farrington, H. B. Nembhard, D. T. Sturrock, and G. W. Evans, 766-773. Piscataway, New Jersey: Institute of Electrical and Electronics Engineers..

Arisha, A. \& P., Young. 2004. "Intelligent simulation-based lot scheduling of photolithography toolsets in a wafer fabrication facility". In Proceedings of the 2004 Winter Simulation Conference, edited by R.G. Ingalls, M. D. Rossetti, J. S. Smith, and B. A. Peters, 1935-1942. Piscataway, New Jersey: Institute of Electrical and Electronics Engineers.

Christopher, M., J. M. Rechard. 1998. Handbook on Architecture of Information Systems, Springer Berlin Heidelberg.

Diamond, R., C. R. Harrell, J. O. Henrikson, W. B. Nordgren, C. D. Pegden, M. W. Rohrer, A. P. Waller, and A. M. Law. 2002. "The current and future status of simulation software (panel)." In Proceedings of the 2002 Winter Simulation Conference, edited by E. Yücesan, C.-H. Chen, J. L. Snowdon, and J. M. Charnes. 1633- 1640. Piscataway, New Jersey: Institute of Electrical and Electronics Engineers.

Ferrin, D. M., M. J. Miller, and D. Muthler. 2005. "Lean sigma and simulation, so what's the correlation? V2." In Proceedings of the 2005 Winter Simulation Conference, edited by M. E. Kuhl, N. M. Steiger, F. B. Armstrong, and J. A. Joines. 2011-2015. Piscataway, New Jersey: Institute of Electrical and Electronics Engineers.

Hicks, B. J. 2007. "Lean information management: Understanding and eliminating waste." International Journal of information Management, 27: 233-249.

Kumar, M., J. Antony, R. K. Singh, M. K. Tiwari \& D.Perry. 2006. "Implementing the lean sigma framework in an Indian SME: a case study.” Production Planning \& Control, 17: 407-423.

Mahfouz, A., S., Hassan \& A., Arisha. 2010. "Practical simulation application: Evaluation of process control parameters in Twisted-Pair Cables manufacturing system". Simulation Modelling Practice and Theory, 18: 471-482.

Mo, J. 2009. "The role of lean in the application of information technology to manufacturing." Computers in Industry, 60: 266-276.

Phadke, S. M., 1989. Quality Engineering Using Robust Design. Prentice Hall, Englewood Cliffs, N.J.

Sahoo, A.K., M. K., Tiwari, and A. R. Mileham. 2008. "Six Sigma based approach to optimize radial forging operations variables". Journal of material processing technology. 202: 125-136.

Shang, J.S., Li, S., Tadikamalla, P. 2004. "Operational design of a supply chain system using Taguchi method, response surface methodology, simulation and optimisation." Int. Journal of Prod. and Res. 42: 3823-3849

Wilson, L.2010. Lean Manufacturing. New York: McGraw-Hill, Inc.

Womack, J. and D. Jones. 1996. Lean Thinking: banish waste and create wealth in your corporation. Simon \& Schuster, New York, NY. 


\section{AUTHORS BIOGRAPHIES}

Amr Mahfouz received his BSc and MSc degrees in Operations Research and Decision Support from faculty of Computers and Information, Cairo University, Egypt.. Currently, he is a senior researcher at 3S Group, Management School, Faculty of Business, DIT. He is also a lecturer in School of Management (DIT). Mr. Mahfouz taught in Institute of Statistical Studies and Research (ISSR) and University of Modern Science and Art (MSA) in Cairo. In addition to his experience in Supply Chain Business Process analysis and SAP implementation when he led Engineering Department in MOBICA (leading manufacturer in office furniture. He has published several journal and international conference articles in the area of supply chain management, modeling, simulation and lean supply chain. His research interest includes supply chain management, simulation modeling applications in business process analysis, supply chain risk analysis and lean supply chain. His email address is amr.mahfouz@dit.ie

John Shea received his BSc in Logistics and Supply Chain Management in 2010, and is currently completing his MSc in Strategic Management with specialization in Innovation in Dublin Institute of Technology. He has many years experience in the retail sector, having worked for a large multinational for several years. His research interests include supply chain management, lean practices in manufacturing and services, modeling and simulation, complex interlinkages of the sales and marketing management functions, new product development methods and commercialization of technology. His email address in john.s.shea@gmail.com.

Amr Arisha, PhD. Dr. Arisha is a 3S Group Director (Research unit in DIT specialized in Smart Sustainable Solutions for complex business processes). He taught in Dublin City University (DCU), Alexandria University, Arab Academy for Science and Technology and Maritime Transport, Dublin Institute of Technology (DIT). He is currently Head of Department of International Business, College of Business at DIT. Dr. Arisha has published over 20 journal and international conference articles in the area of decision support systems for complex business processes in both manufacturing and service sectors. His research includes Business Process Simulation, System dynamics, Optimization, and Operations Excellence applications in Supply Chain Management. Dr. Arisha is a PRINCE2-certified (project management), an accredited FAS trainer since 2005 and completed a higher certificate in training (teaching and learning) in 2007. He is also a chief examiner of Marketing Institute of Ireland (MII). Dr. Arisha has led many projects in the areas of Risk Assessment, Operations Excellence, Supply Chain Management and Capacity Planning in Intel-Ireland and other national and international organizations. His email address is: amr.arisha@dit.ie 